\title{
$\mathrm{ESW}$ 형 해수여과장치의 구동 기어감속기에 대한 내진해석
}

\section{A Seismic Analysis for Driving Gear Reducer of ESW Traveling Sea Water Screen}

\author{
김 창 원*. 이 영 신†.김 흥 태**. 김 지 원** \\ Chang Won Kim, Young Shin Lee, Heung Tae Kim and Jee Won Kim \\ (2011년 10월 12일 접수 ; 2012년 6월 26일 심사완료)
}

Key Words : Seismic Analysis(내진해석), Floor Response Spectrum(FRS ; 층응답스펙트럼), Gear Reducer(기 어감속기), Traveling Sea Water Screen(해수여과장치)

\begin{abstract}
In this study, the safety of the driving gear reducer of ESW(essential service water) traveling sea water screen was evaluated through seismic analysis. Mode analysis of gear reducer was performed for reliability of analysis. Seismic analysis was performed in operating basis earthquake(OBE) and safe shutdown earthquake(SSE), which were applied as design condition using floor response spectrum(FRS). The maximum strain of gear reducer under OBE and SSE were $20.4 \mu$ and $33.6 \mu$, respectively. The maximum stresses were $2.42 \mathrm{MPa}$ under OBE condition and 4.36 MPa under SSE condition, which were smaller than the allowable strength of material.
\end{abstract}

\section{1. 서 론}

원자력 구조물은 지진시에도 높은 안전성을 요구 하기 때문에 구조물의 설계변경 및 장비의 제작 시 내진해석을 수행하여 안전성을 확보하여야 한다. 원 자력 발전소의 경우, 만약의 사고시 방사능 물질의 유출은 막대한 피해를 입히므로 다른 산업 시설에 비하여 엄격하고도 정밀한 내진 설계를 적용하도록 되어있다 ${ }^{(1,2)}$.

기기검증은 일반적으로 온도, 습도, 압력, 방사선 등의 환경조건에 대한 노화시험 및 해석(aging test/

† 교신저자; 정회원, 충남대학교 기계설계공학과

E-mail : leeys@cnu.ac.kr

Tel : (042)821-6644, Fax : (042)821-8906

* 정회원, 충남대학교 대학원 기계설계공학과

** 충남대학교 대학원 기계설계공학과

\# 이 논문의 일부는 2011년 추계 소음진동 학술대회에서 발표되었음. analysis)으로 구성되는 내환경검증과 내진해석 및 시험(seismic analysis/test)으로 구성되는 내진검증 으로 구분할 수 있다(3).

기어감속기는 원자력발전소에 공급되는 해수의 불순물을 걸러내는 여과장치의 구동장치로서 지상 에 설치되어 있으며, 구동모터가 작동하여 기어감속 기를 통해 회전력을 발생시키고 여과망이 설치된 주축 조립체를 구동시킨다. 주축 조립체는 지상으로 부터 해수 밑바닥까지 약 $17 \mathrm{~m}$ 정도의 높이로 설치 되어 여과망을 작동시킨다. 이러한 스크린형 해수여 과장치의 기어감속기는 원자력발전소에 공급되는 해수의 불순물을 계속적으로 여과하기 위한 구동장 치이므로 지진의 발생이나 구조물의 충격이 발생하 였을 때 안전성을 확보해야 하며, 설계시 내진해석 을 수행하고 있다.

이 연구는 울진원자력발전소에 설치하게 될 필수 냉각수(ESW : essential service water)형 해수여과 장치의 구동 기어감속기에 대한 내진해석을 수행하 고 이에 따른 설계의 타당성 검토 및 구조적 안전 
성을 평가하는데 목적이 있다.

내진해석은 ANSYS 13.0 워크벤치를 사용하여 모델링을 하였으며, 운전기준지진 $(\mathrm{OBE})$ 과 안전정지 지진(SSE) 하중조건에 대한 구조물의 지진응답해석 을 수행하였다.

\section{2. 내진해석조건}

\section{1 물성치}

Table 1 은 기어감속기 해석 모델의 기계적 물성 을 나타낸 것이다. 물성치 정보는 ASTM 규격 제 원을 통해 얻을 수 있으며, 해석에 필요한 데이터는 푸아송 비, 탄성계수, 밀도, 항복강도 등이다.

\section{2 지진 허용 응력}

구조물의 재질은 A276-TP316(ASTM 규격)이며, 허용응력은 $\sigma_{y}=205 \mathrm{MPa}$ 이다. 일반적으로 지진하중 을 받는 구조물의 부재 응력검토에 적용되는 허용 응력은 설계지진 준위에 따라 다르다. 운전기준지진 하중은 참고문헌 ${ }^{(4,5)}$ 을 통하여 service level A limit 의 허용응력을 적용하였고, 안전정지지진 하중이 포 함된 하중조합의 경우는 service level D limit의 허 용응력을 적용하였다. 그리고 운전기준지진 하중 하 에서 구조물의 부재들은 항복이 일어나지 않아야 하며, 안전정지지진 하중 하에서는 구조물의 부재가 파손되지 않아야 한다.

상기와 같은 기준에 따라 계산된 허용응력은 다 음과 같다.

(1) 안전정지지진 $(\mathrm{OBE})$ 허용응력

허용 축 인장응력 $\left(\sigma_{t}\right)$ :

$0.6 \sigma_{y}=0.6 \times 205 \mathrm{MPa}=123 \mathrm{MPa}$

허용 굽힘응력 $\left(\sigma_{b}\right)$ :

$0.6 \sigma_{y}=0.6 \times 205=123 \mathrm{MPa}$

허용 전단응력 $(\tau)$ :

$0.4 \sigma_{y}=0.4 \times 205=82 \mathrm{MPa}$

(2) 안전정지지진(SSE) 허용응력

허용 축 인장응력 $\left(\sigma_{t}\right)$ :

$1.5 \times 0.6 \sigma_{y}=1.5 \times 0.6 \times 205 \mathrm{MPa}$ $=184.5 \mathrm{MPa}$

허용 굽힘응력 $\left(\sigma_{b}\right)$ :

$$
1.5 \times 0.6 \sigma_{y}=1.5 \times 0.6 \times 205
$$$$
=184.5 \mathrm{MPa}
$$

허용 전단응력 $(\tau)$ :

$$
1.5 \times 0.4 \sigma_{y}=1.5 \times 0.4 \times 205=123 \mathrm{MPa}
$$

여기서, $\sigma_{y}$ 는 항복응력을 의미하며, 첨자 $t, b$ 는 각 각 인장, 굽힘응력, $\tau$ 는 전단응력을 의미한다.

\section{3 층응답스펙트럼}

Table 2는 구조물이나 복합재료의 $\mathrm{OBE}, \mathrm{SSE}$ 하중 조건하에서 적용할 수 있는 감소율을 나타내고 있다. 해석하고자 하는 essential service water (ESW)계 통은 외부 프레임과 기어 및 모터로 구성되어 있다. 따라서 Table 2의 "Motor, Fan, and Compressor Housings"에 적용하는 댐핑값을 사용하였다. Motor, fan, and compressor housings의 댐핑값은 $\mathrm{OBE}$ 하중 조건하에서 $2 \%, \mathrm{SSE}$ 하중조건하에서는 $3 \%$ 를 사 용하도록 US NRC Regulatory Guide 1.61에 규정 되어 있다 ${ }^{(6)}$.

층응답스펙트럼은 북-남 및 동-서 수직방향에서 고유주기에 대한 최대응답 가속도로 나타낸다. Fig. 1 은 해석에 사용된 북-남 방향에 대한 고도 $109 \mathrm{ft}$ 에서의 층응답스펙트럼이다.

\section{3. 유한요소 해석}

\section{1 해석 모델}

이 연구에서는 상용 유한요소 해석프로그램인 ANSYS 13.0을 사용하여 해석을 위한 유한요소 모 델을 수행하였으며, 모델에 대한 3차원 모델링은 CATIA V5를 통해 모델을 구현하였고 Fig. 2에 나타 내었다. 해석모델은 유한요소의 특성 및 하중의 작 용조건에 따라 단순화 될 수 있다. 모델의 평기어와 헬리컬베벨기어의 경우, 기어이는 생략되어 모델링

Table 1 Mechanical properties of the drive unit assembly and head shaft assembly

\begin{tabular}{c|c}
\hline \hline Material & A276 TP316 \\
\hline Density & $7850 \mathrm{~kg} / \mathrm{m}^{3}$ \\
\hline Poisson's ratio & 0.3 \\
\hline Young's modulus & $210 \mathrm{GPa}$ \\
\hline Yield strength & $205 \mathrm{MPa}$ \\
\hline
\end{tabular}


되었다. 유한요소 모델링에서 기어이를 고려하였을 경우 상세 해석이 가능하나 해석시간이 기하급수적

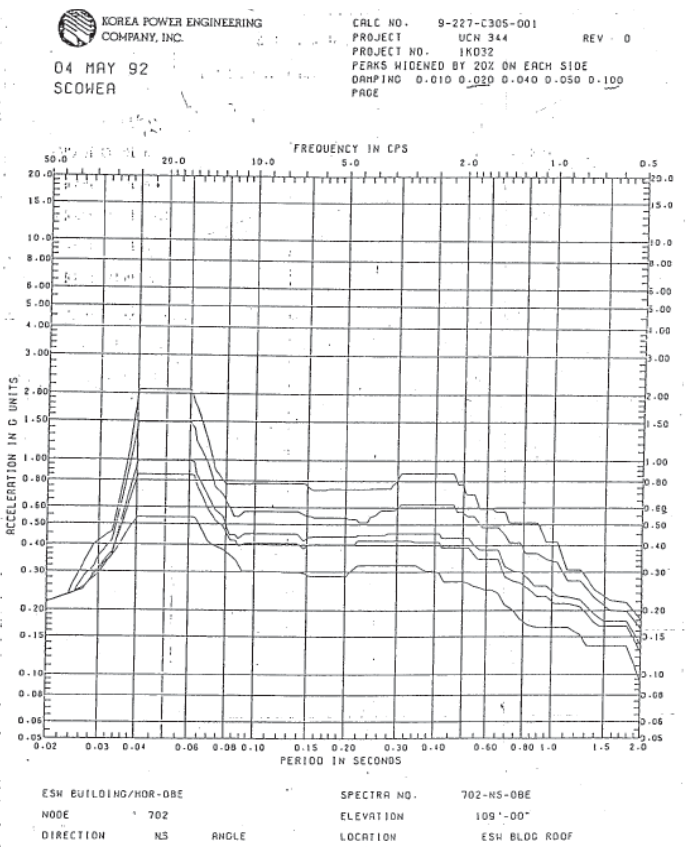

Fig. 1 Floor response spectra interior structure operating Level, EL. 109', OBE, North-South

Table 2 Damping values for mechanical and electrical component ${ }^{(6)}$

\begin{tabular}{c|c|c}
\hline \hline $\begin{array}{c}\text { Structure or } \\
\text { component }\end{array}$ & OBE & SSE \\
\hline $\begin{array}{c}\text { Motor, fan, and } \\
\text { compressor housings } \\
\text { (protection, structural } \\
\text { support) }\end{array}$ & $2 \%$ & $3 \%$ \\
\hline $\begin{array}{c}\text { Pressure vessels, heat } \\
\text { exchangers, } \\
\text { and pump and valve } \\
\text { bodies(pressure } \\
\text { boundary) }\end{array}$ & $2 \%$ & $3 \%$ \\
\hline $\begin{array}{c}\text { Welded instrument } \\
\text { racks(structural } \\
\text { support) }\end{array}$ & $2 \%$ & $3 \%$ \\
\hline $\begin{array}{c}\text { Electrical cabinets, } \\
\text { panels, and motor } \\
\text { control centers } \\
\text { (MCCs) }\end{array}$ & $2 \%$ & $3 \%$ \\
(protection, structural \\
support)
\end{tabular}

으로 증가하게 되므로, 이 해석에서는 모델을 단순 화하여 전체감속기의 응력분포를 파악하는데 주안 점을 두었다. 해석모델인 기어감속기는 5 개의 기어 와 1 개의 구동모터가 존재하여 각각의 기어들은 서 로 접촉하고 있다.

\section{2 경계조건 및 하중조건}

해석모델에서 $\mathrm{X}$ 축은 남-북 방향이고, $\mathrm{Y}$ 축은 동서 방향이며, $\mathrm{Z}$ 축은 수직방향으로 정의하였다. 해석 모델은 도면을 바탕으로 Fig. 2와 같이 생성하였으며 총 요소 수는 약 15000 이다. 경계조건은 기어감속기 의 바닥에서는 $\mathrm{X}, \mathrm{Y}, \mathrm{Z}$ 방향과 회전의 모든 자유도에 대해서 구속하기위해 Fig. 3과 같이 완전구속 경계조 건을 주었다. 하중조건은 $-Z$ 방향으로 $9.81 \mathrm{~m} / \mathrm{s}^{2}$ 의 중 력가속도를 적용하여 기어감속기의 사하중을 고려 하였다.
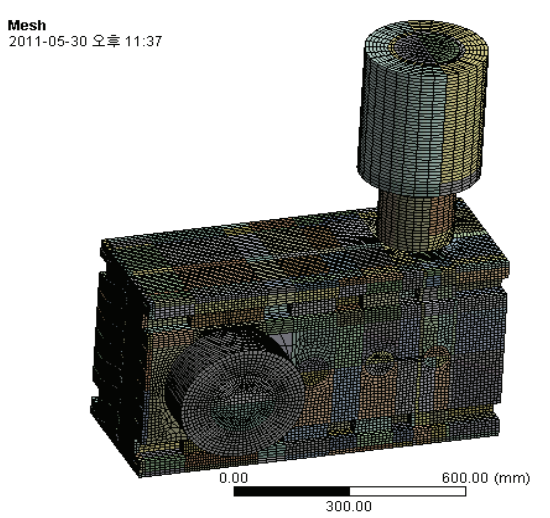

ANSTS 13.0

Fig. 2 FE model of gear reducer

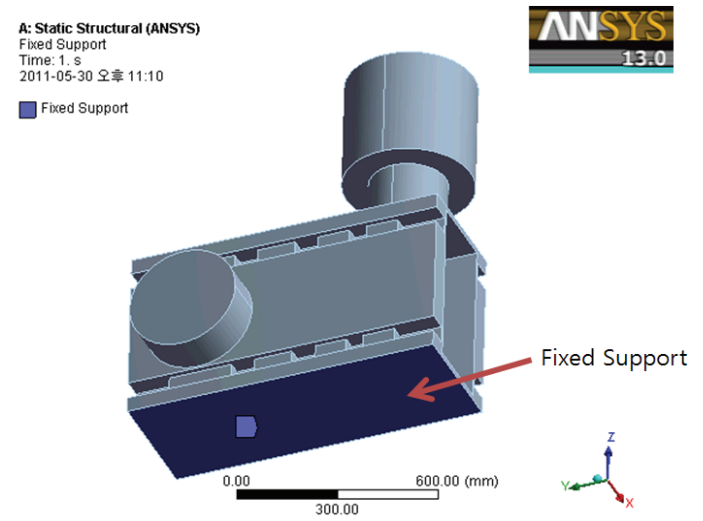

Fig. 3 Boundary condition of gear reducer 
Table 3 Natural frequency of gear reducer

\begin{tabular}{c|c}
\hline \hline Mode number & Frequency(Hz) \\
\hline 1 & 82.85 \\
\hline 2 & 102.45 \\
\hline 3 & 263.64 \\
\hline 4 & 354.56 \\
\hline
\end{tabular}

\section{3 고유치 해석 결과}

기어감속기에 대한 내진해석을 수행하기 전에 고 유치 해석을 수행하였다. 감속기의 1 차 고유진동수 는 $82.85 \mathrm{~Hz}$ 이며, Table 3 은 기어 감속기의 고유진 동수를 1 차부터 4 차까지의 진동수를 보여준다. 모드 1 에 대한 그림은 Fig. 4에 나타나 있다. 여기서 얻 어진 결과들과 응답스펙트럼 해석을 통해서 얻어지 는 가속도 값을 입력 값으로 하여 스펙트럼 해석을 한다. 응답스펙트럼은 남-북, 동-서, 수직 3축방향을 동시에 적용하여 수행하였다. 고유치 해석은 일반적 인 고유치 해석의 경우보다 더 많은 모드 수를 고 려하며, 모드계수가 기준값 이상이 되는 모드들에 대해 모드 조합이 이루어지게 한다 ${ }^{(1)}$. 이를 통해 해 석의 신뢰성을 확보할 수 있다. 이 연구에서는 모드 계수를 0.01 로 설정하였으며, 이는 최대 모드 기여 계수의 크기에 대해서 $1 \%$ 의 크기의 모드 기여 계 수값을 갖는 모드에 대해 모드조합을 수행함을 뜻 하며 총 50 개의 모드에 대한 고유치 해석을 수행하 였다.

\section{4. 내진 해석 결과}

\section{1 변위 및 변형률 해석 결과}

내진 해석을 통해서 기어 감속기의 최대 변위와 변형률을 산출하였다. 발생된 최대 변위는 안전정지 지진 하중에서 $0.1 \mathrm{~mm}$ 수준이다. Fig. 5와 Fig. 6은 각각 운전기준지진 하중과 안전정지지진 하중 하에 서 변형률 분포와 최대 변형률을 나타내고 있다. 최 대 변형률은 운전기준지진 하중과 안전정지지진 하 중 모두 모터와 기어감속기 연결부에서 발생하였다. Table 4는 기어감속기의 $\mathrm{x}, \mathrm{y}, \mathrm{z}$ 방향에 따른 최대 변 형률을 보여준다. 운전기준지진 하중 하에서의 최 대 변형률은 $\mathrm{x}, \mathrm{y}, \mathrm{z}$ 방향에서 각각 $13.7 \mu, 7.4 \mu$, $15.8 \mu$ 이다. 안전정지지진(SSE) 하중 하에서의 $\mathrm{x}, \mathrm{y}$, z방향의 변형률은 각각 $22.9 \mu, 13.5 \mu, 28.7 \mu$ 이다.

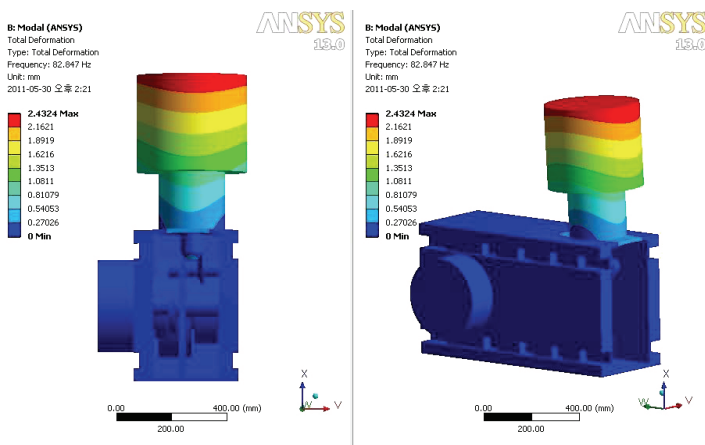

Fig. 4 First mode shape of gear reducer

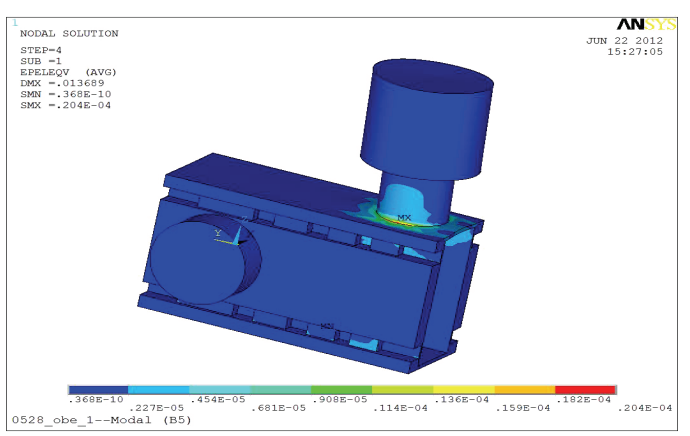

Fig. 5 von Mises strain contour of gear reducer under OBE condition

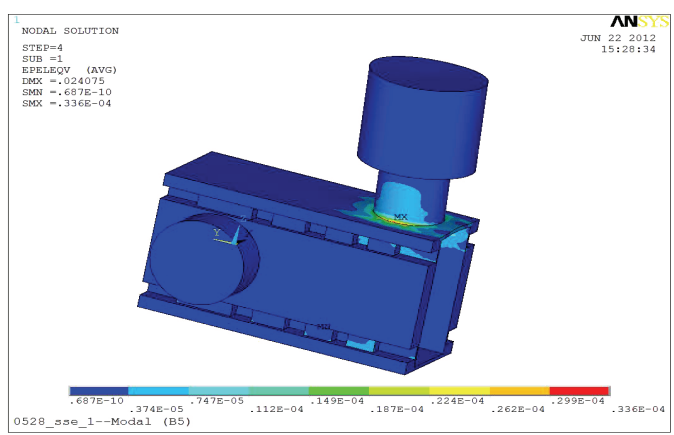

Fig. 6 von Mises strain contour of gear reducer under SSE condition

Table 4 Maximum strain of gear reducer under seismic condition

\begin{tabular}{c|c|c|c|c}
\hline \hline \multirow{2}{*}{$\begin{array}{c}\text { Seismic } \\
\text { load }\end{array}$} & \multicolumn{4}{|c}{ Maximum strain $\left(10^{-6} \mathrm{~mm} / \mathrm{mm}\right)$} \\
\cline { 2 - 5 } & x-direction & y-direction & z-direction & Total \\
\hline OBE & 13.7 & 7.4 & 15.8 & 20.4 \\
\hline SSE & 22.9 & 13.5 & 28.7 & 33.6 \\
\hline
\end{tabular}


Table 5 Maximum stress and allowable stress of gear reducer

\begin{tabular}{c|c|c}
\hline \hline Seismic load & $\begin{array}{c}\text { Maximum } \\
\text { stress(MPa) }\end{array}$ & $\begin{array}{c}\text { Allowable } \\
\text { stress(MPa) }\end{array}$ \\
\hline OBE & 2.42 & 82 \\
\hline SSE & 4.36 & 147 \\
\hline
\end{tabular}

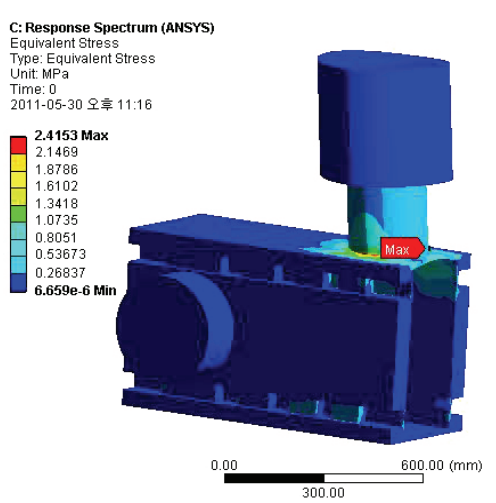

MTSYS

\$3:0

Fig. 7 Stress contour of gear reducer under OBE condition

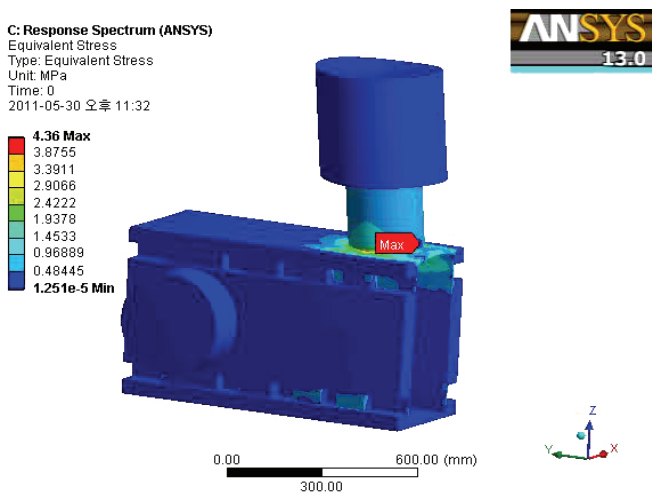

Fig. 8 Stress contour of gear reducer under SSE condition

Total 최대 변형률은 $\mathrm{OBE}, \mathrm{SSE}$ 하중 하에서 각각 $20.4 \mu, 33.6 \mu$ 이며, 강재의 항복 변형률 $2000 \mu$ 와 비교하면 아주 작은 값이다. 따라서 내부 기어장치 에 큰 영향을 미치지 않는 것으로 판단된다.

\section{2 응력 해석 결과}

운전기준지진 하중과 안전정지지진 하중하에서 최대응력은 모터와 기어감속기 연결부에서 공통적
으로 발생하였다. Fig. 7은 운전기준지진 하중 하에 서의 응력분포를 보여주고 있고, Fig. 8은 안전정지 지진 하중 하에서의 응력분포를 나타낸 것이다. Table 5 는 OBE 하중과 SSE 하중하에서의 최대응 력값과 허용응력 값을 나타낸 것이다. 운전기준지진 허용응력값 중 최소치인 허용전단응력이 운전기준 지진 하중하에서는 $82 \mathrm{MPa}$ 이고, 안전정지지진 하중 하에서는 $147 \mathrm{MPa}$ 이다. 따라서 기어 감속기는 지진 이 발생한 상황에서도 안전하다.

\section{5. 결 론}

이 연구에서는 울진원자력발전소에 설치하게 될 $\mathrm{ESW}$ 형 해수여과장치의 구동 기어감속기에 대한 내 진해석을 수행하였으며, 이에 따른 설계의 타당성 검토 및 구조적 안전성을 평가하였다.

미국원자력규제위원회의 규제지침에 의해 원자력 구조물에 대한 운전기준지진 및 안전정지지진 발생 시 구조물을 구성하고 있는 부재나 부품의 응력에 대하여 ASME Section III, Division 1, Subsection $\mathrm{NF}$ 규정에 따라 내진해석 및 구조해석을 수행하였 으며 다음과 같은 결론을 얻었다.

(1) 층응답스펙트럼(floor response spectrum)을 사용하여 내진에 대한 조건을 부여하였으며, 해석결 과 운전기준지진 하중에서의 최대 변위는 0.0137 $\mathrm{mm}$ 이고, 안전정지지진 하중에서의 최대 변위는 $0.0241 \mathrm{~mm}$ 가 발생하였다.

(2) 내진해석 결과 최대응력은 운전기준지진 하 중에서 $2.42 \mathrm{MPa}$ 이고, 안전정지지진 하중에서는 $4.36 \mathrm{MPa}$ 이다. 최대응력은 두 하중조건 모두 모터 와 기어감속기 연결부에서 발생하였다. 기어와 베어 링부의 응력은 $\mathrm{OBE}$ 하중 하에서는 약 $0.2 \mathrm{MPa}$ 에 서 $0.5 \mathrm{MPa}$ 사이의 값을 보이고, $\mathrm{SSE}$ 하중 하에서 는 약 $0.3 \mathrm{MPa}$ 에서 $0.8 \mathrm{MPa}$ 의 값을 보인다. 허용응 력은 ASME SEC III Subsection NF 기준으로 운 전기준지진 하중에서 $82 \mathrm{MPa}$ 이고, 안전정지지진 하 중에서 $147.6 \mathrm{MPa}$ 이므로, 기어감속기에 대한 안전 성을 확보한 것으로 평가하였다.

(3) 구조물의 total 최대 변형률은 $\mathrm{OBE}, \mathrm{SSE}$ 하 중 하에서 각각 $20.4 \mu, 33.6 \mu$ 이며, 강재의 항복 변형률 $2000 \mu$ 와 비교하면 아주 작은 값이다. 따라 
서 내부 기어장치의 큰 영향을 미치지 않는 것으로 판단된다.

\section{참 고 문 헌}

(1) Kim, H. T., Lee, Y. S. and Park, Y. M., 2011, Seismic Analysis of Traveling Sea Water Screen, Journal of COSEIK, Vol. 24, No. 3, pp. 289 294.

(2) Kim, H. T. and Lee, Y. S., 2011, Seismic and Structure Analysis of a Temporary Rack Construction in a Nuclear Power Plant, Trans. of KSME, Series A, Vol. 35, No. 10, pp. 1265 1271.
(3) Byeon, H. S. and Lee, J. K., 2002, Seismic Qualification of the Main Control Board for Nuclear Power Plant, Transactions of the Korean Society for Noise and Vibration Engineering, Vol. 12, No. 3, pp. $856 \sim 863$.

(4) ASME, 1995, Component Supports, ASME Section III Division 1 Subsection NF.

(5) ASME, 1995, Rules for Evaluaion of Service Loadings with Level D Service Limits, ASME Section III Division 1 Appendix F.

(6) US NRC Regulatory Guide 1.61, 1973, Damping Values for Seismic Design of Nuclear Power Plants. 